\title{
AN ETCH HOLE-FREE PROCESS FOR TEMPERATURE-COMPENSATED, HIGH Q, ENCAPSULATED RESONATORS
}

\author{
Eldwin J. $\mathrm{Ng}^{*}$, Yushi Yang, Yunhan Chen, and Thomas W. Kenny
}

Stanford University, Stanford, California, USA

\begin{abstract}
A process is presented for the fabrication of high quality factor (Q), temperature-compensated silicon resonators without release-etch perforations within the epitaxial polysilicon encapsulation (epi-seal). Electrostatically actuated Lamé-mode square resonators up to $400 \mu \mathrm{m}$ wide with frequencies from 8 to $107 \mathrm{MHz}$ are released with no etch perforations, resulting in high $\mathrm{f}-\mathrm{Q}$ products of up to $2 \mathrm{e} 13 \mathrm{~Hz}$. Temperature compensation with a turnover point is achieved using an epitaxially grown, highly boron-doped device layer.
\end{abstract}

\section{INTRODUCTION}

Silicon resonators have been shown to have excellent stability when properly encapsulated [1] and also very high quality factors. Lamé-mode resonators have near-zero thermoelastic dissipation (TED) losses and are known for their high $\mathrm{f}-\mathrm{Q}$ products of $\sim 1.5 \mathrm{e} 13$, believed to be limited by the Akhieser effect [2]. Holes in the device layer for oxide temperature compensation [3] or for device release are generally seen to cause a degradation in the quality factor through TED [4].

To maintain a high $\mathrm{f}-\mathrm{Q}$ product together with passive temperature compensation, the device silicon can be highly doped. Doping with either $\mathrm{p}$ - or n-type dopants has been seen to cause a reduction in the frequency-temperature dependence [5-8], with temperature turnover points previously demonstrated with n-type dopants. This paper demonstrates a similar turnover in highly boron-doped silicon, with a smaller second order temperature coefficient than typically achieved with n-type dopants. High f-Q products are preserved using a process that leaves no etch perforations within the Lamé-mode resonator, and is compatible with the clean, wafer-level epi-seal encapsulation process [9].

\section{FABRICATION}

Good control of the doping concentration for a thick (tens of $\mu \mathrm{m})$ device layer is desirable for manufacturable temperature compensated devices, and can be achieved by growing doped silicon epitaxially on a silicon-on-insulator wafer with a thin device layer. However, significant tensile stress is induced in the crystal for high doping concentrations as a result of the substitution of silicon atoms for smaller boron atoms, which translates to severe wafer bow and unprocessable wafers. To reduce the stress, it is key to note that the stress here arises from the mismatch of the average lattice constant between the seed and the grown layer. Hence, instead of starting with a lightly doped silicon-on-insulator (SOI) device layer and growing highly doped $(\mathrm{p}++)$ silicon epitaxially, it is important to first start with a highly doped device layer. This was achieved by first growing a thin $(2.5 \mu \mathrm{m}), \mathrm{p}++$ $\left(\sim 2 \mathrm{e} 20 \mathrm{~cm}^{-3}\right)$ device layer on a sacrificial wafer and fusion bonding to create an SOI wafer with a $2 \mu \mathrm{m}$ p ++ device layer atop a $2 \mu \mathrm{m}$ layer of buried oxide (Fig. 1a). Vent holes $(\varnothing 0.6 \mu \mathrm{m})$ are defined in this thin layer, and vapor HF is then used to release the buried oxide under large devices (Fig. 1b). Silicon migration and a thick $(18 \mu \mathrm{m}) \mathrm{p}++$ epitaxial silicon deposition at $1130^{\circ} \mathrm{C}$ and 30 torr is used to seal the vent holes and build up the device layer (Fig. 1c). This is followed with the standard epi-seal process, where devices are then patterned into the $\mathrm{p}++$ device layer. $2 \mu \mathrm{m}$ of oxide is deposited over the trenches (Fig. 1d), electrical contact holes are
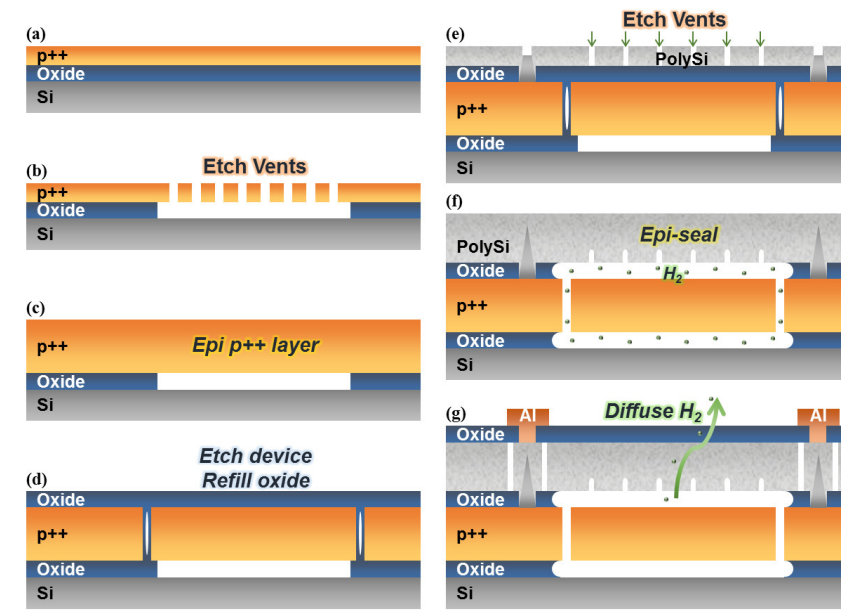

Figure 1. Process for releasing large device areas without etch holes and controlling the doping concentration via epitaxial deposition, with epi-seal encapsulation.

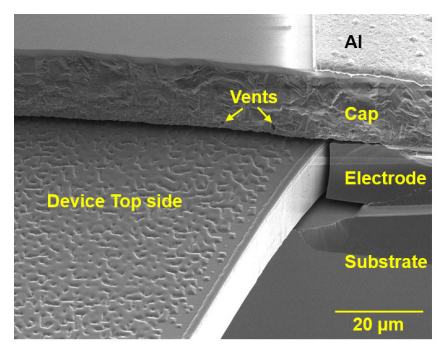

(a)

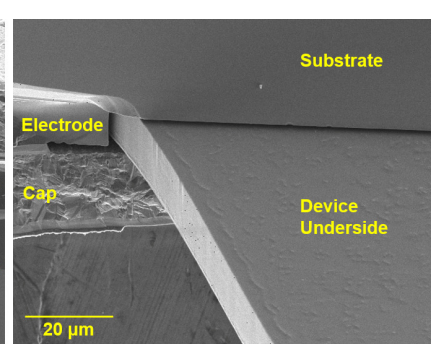

(b)
Figure 2. $45^{\circ}$ SEM images of an encapsulated device free from etch perforations, from (a) the top side and (b) the underside.

etched into the oxide. A first epitaxial polysilicon cap $(5 \mu \mathrm{m})$ is put on, and after etching vents $(\varnothing 0.8 \mu \mathrm{m})$ (Fig. 1e) and releasing the oxide around the device, a second thick layer of polysilicon (20 $\mu \mathrm{m})$ is deposited (Fig. 1f). Electrical contacts vias are then patterned in the cap, and the cavity pressure is lowered to $<1 \mathrm{~Pa}$ by diffusing residual hydrogen out of the cavity (Fig. $1 \mathrm{~g}$ ). The device layer resistivity was measured post-process to be $0.739 \mathrm{~m} \Omega-\mathrm{cm}$.

$45^{\circ}$-view SEM images of the top and bottom surfaces of the encapsulated device (Fig. 2) show no traces of the etched devicelayer vent holes in Fig. 1b. Surface roughness is observed, especially on the top surface of the device and is likely a result of the silicon deposition through the vent holes during the sealing of the cap (Fig. 1f).

\section{RESULTS \\ Quality factors}

Fundamental and higher order Lamé-mode resonators oriented in the $\langle 100\rangle$ and $\langle 110\rangle$ directions, with and without device-layer etch holes $(\varnothing 2 \mu \mathrm{m})$, were characterized in linear operation and are summarized in Table 1. For higher order modes, pull-in (PI) electrodes [10] were used to narrow the transduction gap to reduce the bias voltage required for operation. Frequency sweeps were performed using an Agilent $8753 \mathrm{ES}$ network analyzer at room temperature $\left(\sim 24^{\circ} \mathrm{C}\right)$, and $\mathrm{f}-\mathrm{Q}$ products of between $1 \mathrm{e} 13$ 
Table 1: Lamé-mode resonator designs and test results.

\begin{tabular}{|l|c|c|c|c|c|}
\hline $\begin{array}{c}\text { Edge length }(\mu \mathrm{m}), \\
\text { design features }\end{array}$ & $\begin{array}{c}\text { Crystal } \\
\text { Orientation }\end{array}$ & $\begin{array}{c}\text { Bias voltage, input } \\
\text { power }\end{array}$ & $\begin{array}{c}\text { Frequency } \\
(\mathrm{MHz})\end{array}$ & $\begin{array}{c}\text { Quality } \\
\text { Factor }\end{array}$ & f-Q $(\mathrm{Hz})$ \\
\hline 400 & $<100>$ & $15 \mathrm{~V},-15 \mathrm{dBm}$ & 8.1 & $1.7 \mathrm{M}$ & $1.4 \mathrm{e} 13$ \\
\hline 400 & $<110>$ & $15 \mathrm{~V},-15 \mathrm{dBm}$ & 10.0 & $1.7 \mathrm{M}$ & $1.7 \mathrm{e} 13$ \\
\hline 300 Pull-in & $<110>$ & $30 \mathrm{~V},-40 \mathrm{dBm}$ & 13.4 & $1.2 \mathrm{M}$ & $1.6 \mathrm{e} 13$ \\
\hline 250 & $<100>$ & $25 \mathrm{~V},-15 \mathrm{dBm}$ & 13.0 & $1.5 \mathrm{M}$ & $2.0 \mathrm{e} 13$ \\
\hline 250 & $<110>$ & $35 \mathrm{~V},-15 \mathrm{dBm}$ & 16.1 & $1.0 \mathrm{M}$ & $1.6 \mathrm{e} 13$ \\
\hline $\begin{array}{l}300 \text { Pull-in } \\
\left(3^{\text {rd }} \text { order }\right)\end{array}$ & $<110>$ & $35 \mathrm{~V},-15 \mathrm{dBm}$ & 40.3 & $370 \mathrm{k}$ & $1.5 \mathrm{e} 13$ \\
\hline $\begin{array}{l}300 \text { Pull-in } \\
\left(4^{\text {th }} \text { order }\right)\end{array}$ & $<110>$ & $35 \mathrm{~V},-15 \mathrm{dBm}$ & 53.7 & $380 \mathrm{k}$ & $2.0 \mathrm{e} 13$ \\
\hline $\begin{array}{l}300 \text { Pull-in } \\
\left(8^{\text {th }} \text { order }\right)\end{array}$ & $<110>$ & $70 \mathrm{~V},-15 \mathrm{dBm}$ & 107.3 & $100 \mathrm{k}$ & $1.1 \mathrm{e} 13$ \\
\hline $\begin{array}{l}400 \\
\text { Etch holes }\end{array}$ & $<100>$ & $35 \mathrm{~V},-10 \mathrm{dBm}$ & 9.7 & $80 \mathrm{k}$ & $7.8 \mathrm{e} 11$ \\
\hline $\begin{array}{l}400 \\
\text { Etch holes }\end{array}$ & $<110>$ & $35 \mathrm{~V},-10 \mathrm{dBm}$ & 7.8 & $120 \mathrm{k}$ & $1.1 . \mathrm{e} 12$ \\
\hline
\end{tabular}

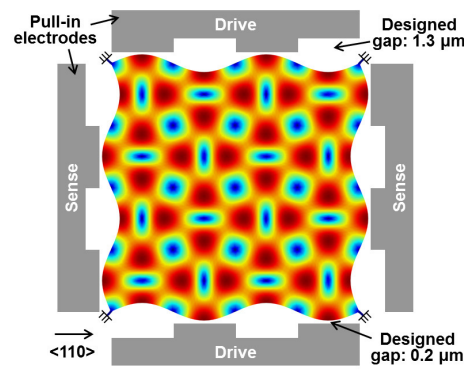

(a)

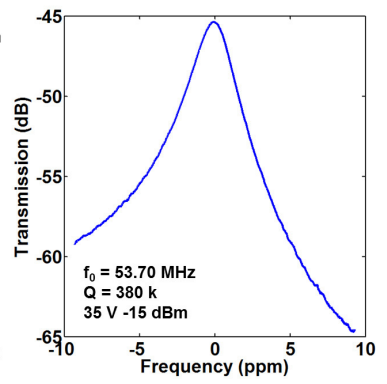

(b)
Figure 3. (a) $4^{\text {th }}$ order resonant Lamé mode shape in the $\langle 110\rangle$ direction with $300 \mu m$ edge length, actuated using pull-in electrodes. (b) Frequency sweep with an $f$-Q product of $2.0 e 13 \mathrm{~Hz}$.

and $2 \mathrm{e} 13 \mathrm{~Hz}$ were consistently observed for the resonators without etch holes. A frequency sweep of the $4^{\text {th }}$ order Lamé mode is shown in Fig. 3. This $\mathrm{f}-\mathrm{Q}$ of $2.0 \mathrm{e} 13 \mathrm{~Hz}$ is about three times as high as achieved in the epi-seal process with limited release areas [11].

\section{Temperature Compensation}

It is seen that highly boron-doped Lamé resonators in the $<100>$ and $<110>$ directions show different frequency-temperature dependences (Fig. 4). Notably, the $<110>$ Lamé resonators have temperature turnover points, with smaller second order temperature coefficients of $\sim-22 \mathrm{ppb} /{ }^{\circ} \mathrm{C}^{2}$ as compared to the typical -65 $\mathrm{ppb} /{ }^{\circ} \mathrm{C}^{2}$ for temperature-compensated n-type resonators [12].

\section{CONCLUSION}

Demonstrated is a process for achieving high quality factor resonators in conjunction with temperature-compensation within an ultra-clean encapsulation process. No residual etch holes are present in the device, allowing for high quality factors. For temperature compensation, epitaxial deposition was used to achieve good control of the device boron doping. Stress effects from the high dopant concentration are mitigated by starting with a highly doped seed. Resonators with $\mathrm{f}-\mathrm{Q}$ products of up to $2.0 \mathrm{e} 13$ $\mathrm{Hz}$ are demonstrated with temperature turnover points.

\section{ACKNOWLEDGEMENTS}

This work was supported by DARPA grant N66001-12-14260, "Precision Navigation and Timing program (PNT)," managed by Dr. Robert Lutwak, and DARPA grant FA8650-13-17301, "Mesodynamic Architectures (MESO)," managed by Dr. Jeff Rogers. The fabrication work was performed at the Stanford Nanofabrication Facility (SNF) which is supported by National Science Foundation through the NNIN under Grant ECS-9731293.



Figure 4. Frequency-temperature dependence of highly borondoped Lamé resonators with fitted temperature coefficients.

\section{REFERENCES}

[1] B. Kim et al., "Frequency Stability of Wafer-Scale Film Encapsulated Silicon Based MEMS Resonators," Sensors and Actuators A, vol. 136, pp. 125-131, May 2007.

[2] S. A. Chandorkar et al., "Limits of Quality Factor in BulkMode Micromechanical Resonators," IEEE MEMS 2008, pp. 74-77, 2008.

[3] V. Thakar and M. Rais-Zadeh, "Temperature-compensated Piezoelectrically Actuated Lamé-mode Resonators," IEEE MEMS 2014, pp. 214-217, Jan 2014.

[4] C. Tu and J. E.-Y. Lee, "Study on Thermoelastic Dissipation in Bulk Mode Resonators with Etch Holes," IEEE NEMS 2012, pp. 478-482, 2012.

[5] J. S. Wang, K. M. Lakin, and A. R. Landin, "Sputtered CAxis Inclined Piezoelectric Films and Shear Wave Resonators," IEEE Freq. Ctrl. Sym. 1983, pp. 144-150, 1983.

[6] A. K. Samarao and F. Ayazi, "Temperature Compensation of Silicon Micromechanical Resonators via Degenerate Doping," IEEE IEDM 2009, pp. 737-740, 2009.

[7] M. Shahmohammadi, B. P. Harrington, and R. Abdolvand, "Turnover Temperature Point in Extensional-Mode Highly Doped Silicon Microresonators," IEEE Trans. Elec. Dev., vol. 60, pp. 1213-1220, Mar 2013.

[8] T. Pensala, A. Jaakkola, M. Prunnila, and J. Dekker, "Temperature Compensation of Silicon MEMS Resonators by Heavy Doping," IEEE Intl. Ultrasonics Symposium 2011, pp. 1952-1955, 2011.

[9] R. N. Candler et al., "Long-Term and Accelerated Life Testing of a Novel Single-Wafer Vacuum Encapsulation for MEMS Resonators," JMEMS, vol. 15, pp. 1446-1456, Dec 2006.

[10] E. J. Ng et al., "Stable Pull-in Electrodes for Narrow Gap Actuation," IEEE MEMS 2014, pp. 1281-1284, 2014.

[11] R. Melamud et al., "MEMS Enables Oscillators with sub-ppm Frequency Stability and sub-ps Jitter," Hilton Head 2012, pp. 66-69, 2012.

[12] A. Jaakkola, M. Prunnila, T. Pensala, J. Dekker, and P. Pekko, "Determination of Doping and Temperature Dependent Elastic Constants of Degenerately Doped Silicon from MEMS Resonators," arXiv: 1401.1363 [cond-mat.mtrl-sci], 2014.

\section{CONTACT}

*E.J. Ng; eldwin@mems.stanford.edu 